\title{
DISSOLUTION TEST FOR GLIBENCLAMIDE TABLETS
}

\author{
Elisabeth Aparecida dos Santos Gianotto*, Renata Pires Arantes, Maurilio José Lara-Filho, Alexandre Cezar Saraiva \\ Casimiro Filho and Marlene Maria Fregonezi-Nery \\ Departamento de Ciências Farmacêuticas, Universidade Estadual de Londrina, CP 6001, 86051-970 Londrina - PR, Brasil
}

Recebido em 18/7/06; aceito em 18/12/06; publicado na web em 30/7/07

\begin{abstract}
DISSOLUTION TEST FOR GLIBENCLAMIDE TABLETS. The aim of this work is to develop and validate a dissolution test for glibenclamide tablets. Optimal conditions to carry out the dissolution test are $500 \mathrm{~mL}$ of phosphate buffer at pH 8.0, paddles at 75 rpm stirring speed, time test set to $60 \mathrm{~min}$ and using equipment with six vessels. The derivative UV spectrophotometric method for determination of glibenclamide released was developed, validated and compared with the HPLC method. The UVDS method presents linearity $\left(r^{2}=0.9999\right)$ in the concentration range of $5-14 \mu \mathrm{g} / \mathrm{mL}$. Precision and recoveries were $0.42 \%$ and $100.25 \%$, respectively. The method was applied to three products commercially available on the Brazilian market.
\end{abstract}

Keywords: glibenclamide; dissolution test; ultraviolet derivative spectrophotometry.

\section{INTRODUCTION}

Dissolution testing is a required test currently used to demonstrate the performance of all solid oral dosage forms in which absorption of the drug is necessary for the product to exert a therapeutical effect.

Dissolution is defined as the process by which a known amount of drug substance goes into solution per unit of time under standardized conditions. Drug dissolution test is a fundamental part of drug product development and manufacturing and is also employed as a quality control tool to monitor batch-to-batch consistency of the drug release from a product.

Glibenclamide (glyburide) (Figure 1) is an oral hypoglycemic agent of the sulphonylurea group used in the treatment of noninsulin dependent diabetes. It has a history of low bioavailability, which is attributed to its poor dissolution properties ${ }^{1}$. As a weak acid with a pKa of 5.3 its solubility strongly depends on the $\mathrm{pH}$ of the test medium and particle size ${ }^{2}$.

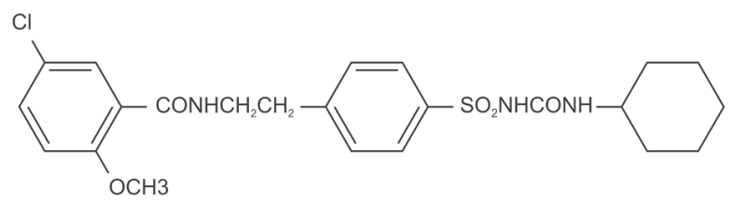

Figure 1. Chemical structure of glibenclamide

Several factors influencing the dissolution of glibenclamide have been examined, such as micronization ${ }^{3}$, solid dispersion and lyophilization $^{4}$, incorporation of surfactants and co-solvents ${ }^{5}$, coprecipitation with polyvinylpyrrolidone ${ }^{6}$, preparation of polymorphic form ${ }^{7}$ and media that simulate the fasted and fed states $^{2}$. Other approaches usually used in the design of dissolution media of poorly soluble drugs include: bringing about drug solubility by increasing the aqueous sink volume or removing the dissolved drug and alteration of $\mathrm{pH}$ to enhance the solubility of ionizable drug molecules ${ }^{2,5}$.

For dissolution testing, a borate buffer $\mathrm{pH} 9.0$ has been tentatively recommended by the $\mathrm{FDA}^{8}$. However, such a high $\mathrm{pH}$

*e-mail: gianotto@uel.br value is of little relevance to the physiological conditions of drug dissolution sites in the body and may reduce the discriminating power of the dissolution test.

The United States Pharmacopeial Forum ${ }^{9}$ indicates conditions for the dissolution test. It uses $0.5 \%$ hexadecyltrimethylammonium bromide in $0.025 \mathrm{M}$ alkaline borate buffer, at $\mathrm{pH}$ 8.0. The dissolution medium was $900 \mathrm{~mL}$, paddle apparatus at the stirring speed of 75 rpm and time test set on 60 min by employing the procedure set forth in the assay. However, HPLC determination and the use of surfactants may increase the cost of the analysis when applied for routine quality control, once a simple, rapid and cost effective analytical method is preferred.

Several assay techniques have been described for quantitative determination of glibenclamide in biological fluids; these include procedures based on high performance liquid chromatography (HPLC $)^{10-18}$, fluorometry ${ }^{19}$, radioimmunoassay ${ }^{20-22}$ and gas chromatography ${ }^{23}$. A few reports deal with the analysis of the drug in these dosage forms; such procedures include: micellar electrokinetic capillary chromatography ${ }^{24}$, RP-HPLC ${ }^{15,25}$, fluorometry ${ }^{26}$, TLC-UV spectrophotometry ${ }^{27}$, derivative spectrophotometry ${ }^{28}$, UV spectrophotometry ${ }^{29}$ and colorimetry ${ }^{30}$.

At the present time there is no dissolution test for glibenclamide tablets reported in any pharmacopeia. So, for all these considerations, the aim of this study was the development and validation of a dissolution test for glibenclamide tablets of three different manufacturers. The other objective was to optimize and validate a simple derivative ultraviolet spectrophotometric (UVDS) method for determination of glibenclamide quantity released in the dissolution medium and compare the results with those obtained by using high performance liquid chromatographic method (HPLC) described in the USP Pharmacopeia ${ }^{31}$ for drug determination in tablets.

\section{EXPERIMENTAL}

\section{Materials}

The standard of glibenclamide was purchased in USP (batch: 29550G). Other reagents and solvents used are: monobasic ammonium phosphate, monobasic potassium phosphate, boric acid and potassium chloride (analytical grade) and acetonitrile (HPLC 
grade). All chemicals were used without further purification. Ultra pure water was obtained from a Milli-Q ${ }^{\circledR}$ Plus apparatus (Millipore ${ }^{\circledR}$ ) and was used to prepare all solutions for the HPLC method. Distilled water was used to prepare all solutions for the UVDS method. The monobasic potassium phosphate buffer $\mathrm{pH} 7.6$ and 8.0 and the borate buffer pH 9.4 were prepared as described in the USP 29. Samples used in the research are commercially available tablets containing $5.0 \mathrm{mg}$ of glibenclamide/tablet: Sample A (reference product), Sample B (generic product) and Sample C (similar product).

\section{Apparatus and conditions}

\section{UVDS method}

The analysis was performed on a Shimadzu Model 160-A UVvisible double-beam spectrophotometer using $1 \mathrm{~cm}$ quartz cells, with a slit width of $2 \mathrm{~nm}$. The suitable conditions for the first-derivative UV spectrophotometric analysis were: $\Delta \lambda=6.4 \mathrm{~nm}$, range of 200 to $350 \mathrm{~nm}$, absorbance at $239 \mathrm{~nm}$ (zero-peak) and monobasic potassium phosphate buffer ( $\mathrm{pH}$ 8.0) as blank.

\section{Sample preparation}

An amount equivalent to $25.0 \mathrm{mg}$ of glibenclamide (samples $\mathrm{A}, \mathrm{B}$ and $\mathrm{C}$ ) was weighed, transferred to a $50.0 \mathrm{~mL}$ volumetric flask and dissolved in sodium hydroxide solution (0.2 M) (500.0 $\mu \mathrm{g} / \mathrm{mL}$ ). A $5.0 \mathrm{~mL}$ aliquot of this solution was transferred into 100.0 $\mathrm{mL}$ volumetric flasks and diluted with phosphate buffer solution $\mathrm{pH} 8.0$ to volume and mixed $(25.0 \mu \mathrm{g} / \mathrm{mL})$.

\section{Standard preparation}

A standard solution containing $25.0 \mu \mathrm{g} / \mathrm{mL}$ was prepared as previous described for sample solution preparation.

\section{HPLC method}

A Varian HPLC system consisting of a Model ProStar 230 liquid chromatograph, and a variable wavelength detector Model ProStar 330 were used. Automatic injections were made by means of Model ProStar 410. The detector wavelength was set at $254 \mathrm{~nm}$. The chromatographic separations were performed at $30{ }^{\circ} \mathrm{C}$ in a $5 \mu \mathrm{m}$ ChromSpher ${ }^{\circledR}$ C8 column (4.6 mm i.d. x $250 \mathrm{~mm}$ ) using a mobile phase of monobasic ammonium phosphate $(0.2 \mathrm{M})$ - acetonitrile $(\mathrm{pH} 5.25 \pm 0.3)(45: 55 \mathrm{v} / \mathrm{v})$, at a flow rate of $2.0 \mathrm{~mL} / \mathrm{min}$. The mobile phase was prepared daily, filtered through a $0.45 \mu \mathrm{m}$ membrane filter (Millipore ${ }^{\circledR}$ ) and sonicated before use.

\section{Sample preparation}

An accurately weighed amount of tablet powder equivalent to $12.5 \mathrm{mg}$ of glibenclamide (samples A, B and C) was transferred to a $25 \mathrm{~mL}$ volumetric flask to which $20.0 \mathrm{~mL}$ of acetonitrile was added and sonicated for $5 \mathrm{~min} ; 5.0 \mathrm{~mL}$ of water was added, agitated and centrifuged. A $5.0 \mathrm{~mL}$ aliquot of supernatant was transferred into $100.0 \mathrm{~mL}$ volumetric flasks $(25.0 \mu \mathrm{g} / \mathrm{mL})$, diluted with mobile phase to volume and mixed.

\section{Standard preparation}

A standard solution containing $25.0 \mu \mathrm{g} / \mathrm{mL}$ was prepared as previous described for sample solution preparation.

All working standard solutions were prepared by diluting the stock standard solution in appropriate concentrations.

\section{Dissolution test}

All dissolution tests were performed using an Erweka DT-6 dissolution tester (six vessels) in accordance with the United States Pharmacopeia (USP) general method $<711>$.
Dissolution studies on three commercially available products (tablets) of glibenclamide were conducted using USP apparatus 2 (paddle method). The dissolution medium was 500 and $900 \mathrm{~mL}$ of either monobasic potassium phosphate USP buffer ( $\mathrm{pH} 7.6$ and 8.0) or borate buffer ( $\mathrm{pH} 9.4$ ) at $37 \pm 0.5^{\circ} \mathrm{C}$, stirred at 50 and $75 \mathrm{rpm}$. In all experiments, $5 \mathrm{~mL}$ sample aliquots were withdrawn at 15,30 , 45, 60, 90 and 120 min using a hypodermic glass syringe equipped with a stainless steel needle, and replaced with equal volume of the fresh medium to maintain constant total volume. The solutions were immediately filtered through a $0.45 \mu \mathrm{m}$ membrane. Drug release (DR\%) was assayed by UVDS method. Cumulative percentages of the dissolved drug from the tablets were calculated and plotted versus time.

\section{Validation of the UVDS and HPLC method}

Both methods were validated according to guidelines of the International Conference on Harmonization ${ }^{32}$ and the RDC $n^{\circ} 899^{33}$. $F$ and $t$ tests were used to compare the proposed method.

\section{Linearity}

The calibration curve was obtained at five concentration levels of glibenclamide $(8.0-12.0 \mu \mathrm{g} / \mathrm{mL})$ for the HPLC method and ten concentration levels $(5.0-14.0 \mu \mathrm{g} / \mathrm{mL})$ for the UVDS method. The linearity was analyzed using the least square regression method with triplicate determinations at each concentration level.

\section{Precision}

Precision of the methods were determined by intra-day repeatability, which was evaluated through the analysis of six standard solutions $(10.0 \mu \mathrm{g} / \mathrm{mL}$ for UVDS and HPLC methods).

\section{Accuracy}

Accuracy of the methods was performed using the standard addition method: $5.0 \mathrm{~mL}$ aliquots of sample solution $(25.0 \mu \mathrm{g} / \mathrm{mL})$ were transferred into $25.0 \mathrm{~mL}$ volumetric flasks containing 3.0 , 5.0 and $7.0 \mathrm{~mL}$ of glibenclamide standard solution $(25.0 \mu \mathrm{g} / \mathrm{mL})$. The solutions were diluted to volume with phosphate buffer solution pH 8.0 and mobile phase for UVDS and HPLC methods, respectively. These final solutions contain 8.0, 10.0 and $12.0 \mu \mathrm{g} /$ $\mathrm{mL}$. All solutions were prepared in triplicate and analyzed.

\section{Specificity}

It was determined for both UVDS and HPLC methods and evaluated by analyzing placebos, wherein the sample matrix without the analyte was analyzed. The system response was examined for the presence of interference or overlaps in the glibenclamide responses.

\section{RESULTS AND DISCUSSION}

\section{Validation of UVDS and HPLC methods}

Analytical characteristics of the proposed UVDS method were evaluated comparing to the HPLC method described in the USP Pharmacopeia, $29^{\text {th }}$ ed. for assay dosage form.

In the range 200 to $350 \mathrm{~nm}$, the absorption of light of a $1 \mathrm{~cm}$ layer of glibenclamide and placebo in phosphate buffer solution pH 8.0 exhibits presence of placebo interference (Figure 2).

Derivative spectral analysis is often used for peak identification due to its advantages in differentiating closely adjacent absorption peaks, identifying weak absorption peaks obscured by sharp peaks, and also wavelength at maximum absorbance for broad spectra ${ }^{34}$.

Figure 3 shows the first derivative spectrum of glibenclamide 


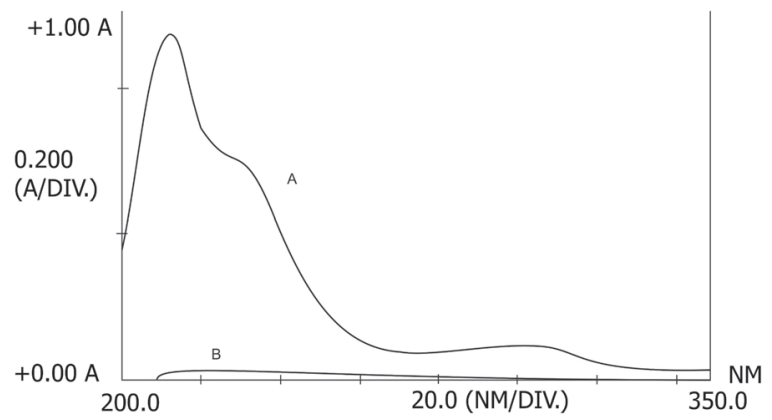

Figure 2. Typical zero-order spectrum of: A - glibenclamide and B - placebo in phosphate buffer solution $\mathrm{pH} 8.0(10 \mu \mathrm{g} / \mathrm{mL})$

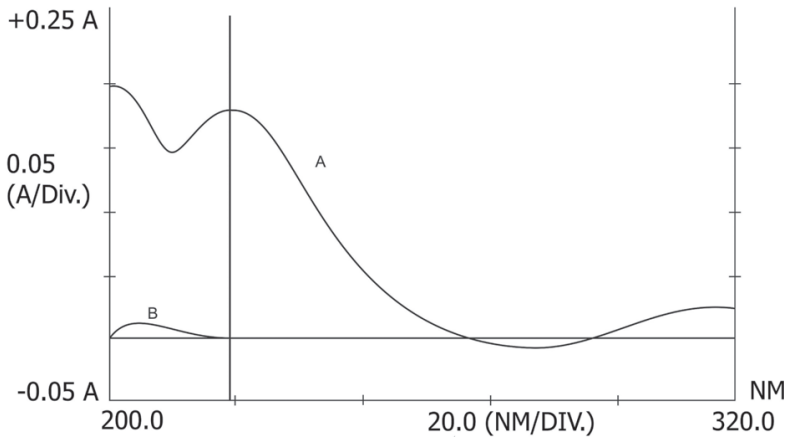

Figure 3. First derivative spectrum of: A - glibenclamide and B - placebo in phosphate buffer solution $\mathrm{pH} 8.0(10 \mu \mathrm{g} / \mathrm{mL})$

which allows determination at $239 \mathrm{~nm}$ by zero-peak measurement without interference of placebo.

The UVDS and HPLC methods showed good linearity at the concentrations of $5.0-14.0$ and $8.0-12.0 \mu \mathrm{g} / \mathrm{mL}$, respectively (Table 1). The least square regression showed excellent correlation coefficient $\mathrm{r}^{2}=0.9999$ (UVDS) and $\mathrm{r}^{2}=0.9988$ (HPLC). The precision of the method was determined by repeatability (intra-day) and was expressed

Table 1. Linearity and precision for UVDS and HPLC methods

\begin{tabular}{lcc}
\hline & UVDS & HPLC \\
\hline Slope & -0.0158182 & 9803.1 \\
Intercept & 0.01354545 & 14848.8 \\
Correlation coefficient $\left(\mathrm{r}^{2}\right)$ & 0.9999 & 0.9988 \\
\hline
\end{tabular}

Table 2. Recovery percentage for UVDS and HPLC methods $(n=9)$

\begin{tabular}{lcc}
\hline Sample & UVDS $(\%)$ & HPLC $(\%)$ \\
\hline A & 99.01 & 98.22 \\
B & 100.91 & 98.79 \\
C & 100.85 & 100.17 \\
\hline
\end{tabular}

as relative standard deviation (RSD) of a series of measurements $(n=6)$. The RSD percentages of the UVDS and HPLC methods were 0.42 and $0.60 \%$, respectively. Good accuracy of the methods was verified by recovery of glibenclamide (Table 2).

Through an analysis of variance (ANOVA) (Table 3), the validation of a linear model and the statistical significance of the curve adjusted by $\mathrm{F}$ value below the value tabulated at $95 \%$ confidence level can be observed, showing that the linear module is well adjusted within the studied concentration range.

\section{Development of the dissolution test}

\section{Selection of test conditions}

According to USP, dissolution medium may be water, a buffered aqueous solution (typically $\mathrm{pH} 4.0$ to 8.0 ) or a dilute acid solution ( 0.001 to $0.1 \mathrm{~N} \mathrm{HCl})$. Surfactants and electrolytes may also be added to increase in the solubilization of the active ingredient. Dissolution testing conditions were selected based on a screening study using USP apparatus 2.

USP apparatus 2 was chosen due to its acceptance as a standard procedure for tablet formulations. Paddle speeds of 50 and $75 \mathrm{rpm}$ were evaluated with aliquots taken $15,30,45,60,90$ and $120 \mathrm{~min}$ after the beginning of paddle rotation.

Figure 4 show the dissolution profiles for glibenclamide in sample A using buffer solutions of $\mathrm{pH} 7.6,8.0$ and 9.4.

At the beginning of the test, better sample dissolution rate is observed at $\mathrm{pH}$ 9.4. However, $45 \mathrm{~min}$ after the beginning of the test, the dissolution profile showed no difference in the liberation of the active substance either at $\mathrm{pH} 9.4$ or $\mathrm{pH}$ 8.0. Since dissolution characteristics of the formulation are to be evaluated over the physiologic $\mathrm{pH}$ range, the selected dissolution medium was phosphate buffer $\mathrm{pH}$ 8.0.

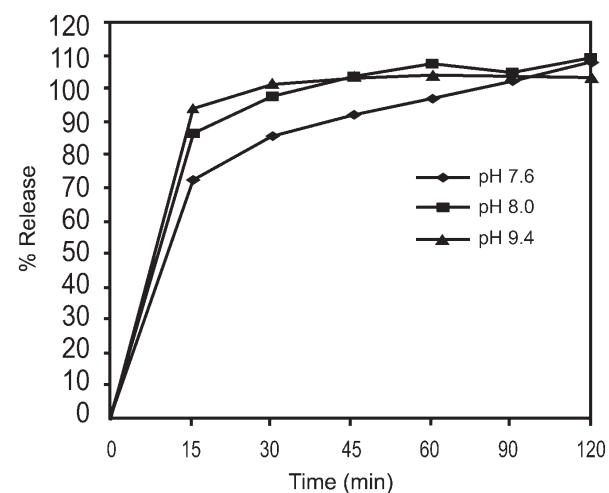

Figure 4. Dissolution profile of glibenclamide tablets (reference sample (Sample A))

As it can be observed in Figure 5, the results of the tests carried out at the speed of $75 \mathrm{rpm}$ showed better glibenclamide dissolution.

Table 3. Analysis of variance of linearity data for UVDS and HPLC methods

\begin{tabular}{|c|c|c|c|c|c|c|}
\hline Method & Source & GL & SQ & MQ & $\mathrm{F}$ & Signification $\mathrm{F}$ \\
\hline \multirow[t]{3}{*}{ UVDS } & Regression & 1 & 0.015137045 & 0.015137 & 65297.06 & $6.15817 \times 10^{-17}$ \\
\hline & Residue & 8 & $1.85455 \times 10^{-6}$ & $2.32 \times 10^{-7}$ & & \\
\hline & Total & 9 & 0.0151389 & & & \\
\hline \multirow[t]{3}{*}{ HPLC } & Regression & 1 & 961007696.1 & $9.61 \times 10^{8}$ & 128.2555 & 0.001476722 \\
\hline & Residue & 3 & 22478744.7 & 7492915 & & \\
\hline & Total & 4 & 983486440.8 & & & \\
\hline
\end{tabular}

GL - degrees of freedom; SQ - square sum; F - test of Snedocor; MQ - mean square 


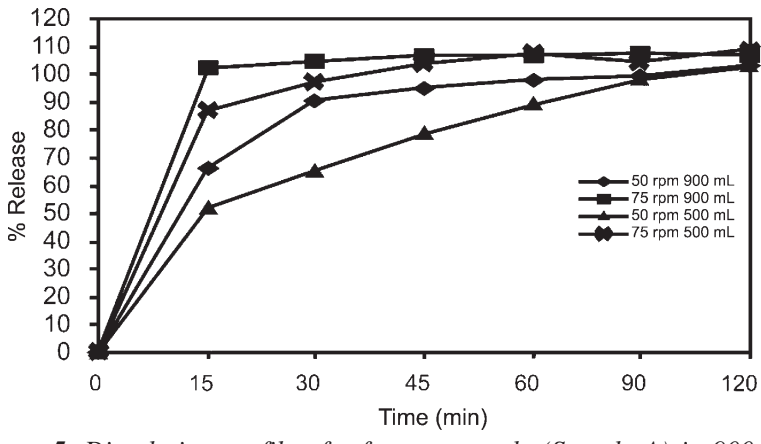

Figure 5. Dissolution profile of reference sample (Sample A) in 900 and $500 \mathrm{~mL}$ of dissolution medium and paddle speeds of 50 and $75 \mathrm{rpm}$

Using a dissolution volume of $900 \mathrm{~mL}$, total dissolution occurred within $15 \mathrm{~min}$, whereas with $500 \mathrm{~mL}$ it occurred within $60 \mathrm{~min}$. However, after $50 \mathrm{~min}$ the dissolution percentage reached $100 \%$ using the same volume.

With the obtained results, the following parameters for dissolution assays of glibenclamide tablets were defined: dissolution medium: monobasic potassium phosphate buffer solution $\mathrm{pH}$ 8.0; dissolution volume: $500 \mathrm{~mL}$; paddle speed: $75 \mathrm{rpm}$; and test time: $60 \mathrm{~min}$.

\section{Filter suitability}

Filter suitability was evaluated using sample A. Aliquots of the three dissolution vessels that were withdrawn and filtered through $0.45 \mu \mathrm{m}$ membrane and aliquots of the other three dissolution vessels were centrifuged for $15 \mathrm{~min}$ at $3000 \mathrm{rpm}$. The dissolved percentage was measured using the UVDS method. The results obtained from filtered and centrifuged sample solutions (98.0-102.0\%) showed that the filter does not interfere in the result of the analysis.

\section{Solution stability}

Standard solutions of glibenclamide and samples obtained as described in section 2.2 were stored unprotected from light, at ambient conditions and assayed against a recently prepared standard solution. All assay results were within $98.0-102.0 \%$ of the initial value. These experiments demonstrate that standard and samples are stable under the conditions of the test for at least $24 \mathrm{~h}$.

\section{Application of dissolution testing in commercial samples}

With the definition of parameters for the dissolution assay, the method was applied to commercial samples (A, B and C) using HPLC and UV derivative spectrophotometric methods to determine the percentage of dissolved glibenclamide (DR \%). The results can be observed in Table 4. All samples were approved in the first level since no unit presented Q value $<80 \%$.

Table 4. Samples A, B and C dissolution test results $(n=6)^{\mathrm{a}}$ using UVDS and HPLC method

\begin{tabular}{lcc}
\hline Sample & UVDS $(\mathrm{DR} \%)$ & HPLC $(\mathrm{DR} \%)$ \\
\hline A & $101.88(96.24-109.39)$ & $97.77(94.40-104.92)$ \\
B & $98.58(96.78-101.41)$ & $102.58(98.20-105.86)$ \\
C & $98.60(96.69-101.68)$ & $102.76(99.33-106.78)$ \\
\hline
\end{tabular}

${ }^{a}$ The average result is reported followed by the range in parenthesis.

The analysis of variance of the results obtained in the application of dissolution testing using UVDS and HPLC methods to determine the percentage of dissolved glibenclamide show that there is no significant difference neither between the methods nor between the tested products $(\mathrm{A}, \mathrm{B}$ and $\mathrm{C})$.

\section{CONCLUSION}

From this study, it was possible to establish dissolution testing parameters which could be used as an alternative of the method indicated in the United States Pharmacopeial Forum ${ }^{9}$ for dissolution test of glibenclamide tablets.

The dissolved percentage was determined by UVDS and HPLC method and the results show no significant difference $(\mathrm{P}>0.05)$ when applied to commercial samples from three different manufacturers.

The method demonstrated to be adequate to be used in quality control of glibenclamide tablets since there is not a dissolution test indicated in official literature.

\section{ACKNOWLEDGEMENTS}

We acknowledge CNPq (Conselho Nacional de Pesquisa - Brasil) for finantial support by means of a student fellowship.

\section{REFERENCES}

1. Talka, P. G.; Anal. Profiles Drug Subst. 1981, 10, 337.

2. Lobenberg, R.; Kramer, J.; Shah, V. P.; Amidon, G. L.; Dressman, J. B.; Pharm. Res. 2000, 17, 439.

3. Lehto, P.; Laine, K.; Kivisto, K. T.; Neuvonen, P. J.; J. Pham. Pharmacol. 1996, $48,899$.

4. Betageri, G. V.; Makarla, K. R.; Int. J. Pharm. 1995, 126, 155.

5. El-Massik, M. A.; Darwish, I. A.; Hassan, E. E.; El-Khaordagui, L. K.; Int. J. Pharm. 1996, 140, 69.

6. Iwata, M.; Ueda, H.; Drug Dev. Ind. Pharm. 1996, 22, 1161.

7. Panagopoulou-Kaplani, A.; Malamataris, S.; Int. J. Pharm. 2000, 195, 239.

8. Noory, C.; Tran, N.; Ouderkirk, L.; Shah, V.; Diss. Technol. 2000, 3, 1.

9. United States Pharmacopeial Forum 2002, 28, 60.

10. Huang, Z.; Li, Y.; Zheng, Q.; Bi, Q.; Wu, Y. Zhongguo Yiyuan Yaoxue Zazhi 2004, 24, 22.

11. Ben-Mei, C.; Yi-Zeng, L.; Fang-Qiu, G.; Lan-Fang, H.; Fu-Liang, D.; YaLi, C.; Xin, W.; Anal. Chim. Acta 2004, 514, 185.

12. Niopas, I.; Daftsios, A. C.; J. Pharm. Biomed. Anal. 2002, 28, 653.

13. Shehata, M. A M.; Mohamed, M. Y.Y.; Abdel Bary, A.; Bull. Fac. Pharm. 2000, 38, 7 .

14. Rabbaa-Khabbaz, L.; Abi Daoud, R.; Karam-Sarkis, D.; Atallah, C.; Zoghbi, A.; J. Liq. Chromatogr. Relat. Technol. 2005, $28,3255$.

15. Venkatesh, P.; Harisudhan, T.; Choudhury, H.; Mullangi, R.; Srinivas, N. R.; Biomed. Chromatogr. 2006, 20, 1043.

16. Xia, C.; Xiong, Y.; Kuang, X.; Li, Y.; Yaowu Fenxi Zazhi 2005, 25, 902.

17. Qin, X.; Hu, G.; Qiu, X.; Zhongguo Gonggong Weisheng 2005, 21, 350

18. Li, X.; Wang, G.; Wang, S.; Zhongguo Yaoke Daxue Xuebao 2004, 35, 532.

19. Girgis, P. T.; Joshi, S. R.; Mahbouba, M.; Analyst 1982, 107, 1246.

20. Lindner, G.; Reinauer, H.; Workshop Rahmen Kongr. Laboratoriums-med. 1980, 4, 34.

21. Glogner, P.; Heni, N.; Nissen, L.; Arzneim. Forsch. 1977, 27, 1703.

22. Glogner, P.; Burmeister, P.; Heni, N.; Klin. Wochenschr. 1973, 51, 352.

23. Castoldi, D.; Tofanetti, O.; Clin. Chim. Acta 1979, 93,195.

24. Feng-Mei, H.; Zhi-yong, C.; Min, C.; Yong, C.; Zhongguo hua xue hui 2000, 18, 456 .

25. Khanolkar, D. H.; Shinde, V. M.; Indian Drugs 1999, 36, 739.

26. Rau, H. L.; Aroor, A. R.; Rao, P. G.; Eastern Pharmacist 1993, 36, 175.

27. Bhushan, R.; Gupta, D.; Jain, A.; J. Planar Chromatogr-Mod. TLC 2006, 19, 288.

28. Bedair, M. M.; Korany, M. A.; Ebdel-Hay, M. A.; Gazy, A. A.; Analyst 1990, 115, 449.

29. Sankar, D. G.; Kumar, J. M. R.; Latha, P. V. M.; Asian J. Chem. 2005, 17, 1334.

30. Lopez, A. M. M.; Felizola, A. C.; Hernandez, V. O. C.; Cuartero, T. M. C.; Rev. Mex. Cienc. Farm. 2005, 36, 33.

31. United States Pharmacopeia, $29^{\text {th }}$ ed., Unites States Pharmacopeial Convention: Rockville, 2006.

32. International Conference on Harmonization (ICH), Validation of analytical Procedures: Text and Methodology; Q2(R1), 2005.

33. Agência Nacional de Vigilância Sanitária; RE no 899 de 29 de maio de 2003.

34. Fuke, C.; Ameno, K.; Ameno, S.; Igaku no Ayumi 1988, 7, 657. 